06;09;13

\title{
Топография поверхности и оптические характеристики тонких пленок AIN на подложке GaAs (100), полученных методом реактивного ионно-плазменного распыления
}

\author{
(C) E.В. Фомин ${ }^{1,2}$, А.Д. Бондарев ${ }^{2}$, A.I. Rumyantseva ${ }^{3}$, T. Maurer $^{3}$, Н.А. Пихтин ${ }^{2}$, С.A. Тарасов ${ }^{1}$ \\ ${ }^{1}$ Санкт-Петербургский государственный электротехнический университет „ЛЭТИ“, Санкт-Петербург, Россия \\ ${ }^{2}$ Физико-технический институт им. А.Ф. Иофрфе РАН, Санкт-Петербург, Россия \\ ${ }^{3}$ Laboratoire de Nanotechnologie et d'Instrumentation Optique, ICD CNRS UMR 6281, Université de Technologie de Troyes, \\ Troyes, France \\ E-mail: evgeny.fomin@bk.ru
}

Поступило в Редакцию 16 октября 2018 г.

В окончательной редакции 3 декабря 2018 г.

Принято к публикации 12 декабря 2018 г.

\begin{abstract}
Представлены результаты исследования топографии поверхности и оптических характеристик тонких пленок AlN, применяющихся в качестве пассивирующих и просветляющих покрытий, осажденных на подложки $n$-GaAs (100) методом реактивного ионно-плазменного распыления. Обнаружено, что условия проведения процесса влияют на структуру и оптические характеристики получаемых пленок, что позволяет получать покрытия с заданными параметрами. Анализ результатов эллипсометрии и атомно-силовой микроскопии поверхности показывает, что показатель преломления пленок коррелирует с текстурой поверхности.
\end{abstract}

DOI: 10.21883/PJTF.2019.05.47396.17564

Нитрид алюминия представляет большой интерес в качестве материала для нанесения тонкопленочных покрытий на торцевые резонаторы (зеркала) мощных полупроводниковых лазеров, выращенных на основе твердых растворов $\mathrm{AlGaAs}$, излучающих на длине волны $820 \mathrm{~nm}$. Известно, что содержащийся в активной области лазера алюминий [1] окисляется при контакте с кислородом. Это приводит к возникновению энергетических состояний в запрещенной зоне лазерной структуры, что в свою очередь ведет к паразитному поглощению генерируемого излучения при его выходе из торцевого резонатора лазера, возникновению безызлучательной рекомбинации и в дальнейшем к деградации зеркала и выходу лазера из строя [2,3]. Один из методов борьбы с деградацией зеркал - нанесение на поверхность торцевого резонатора лазерной гетероструктуры пассивирующих поверхностные состояния покрытий [2-5]. С другой стороны, существует необходимость наносить на торцевые грани резонатора просветляющие и отражающие покрытия, чтобы обеспечить генерацию и вывод когерентного излучения. Часто применяемые для этой цели пленки на основе $\mathrm{Al}_{2} \mathrm{O}_{3}$ или $\mathrm{Si} / \mathrm{SiO}_{2}$ имеют в своем составе кислород, который может мигрировать из пленки в глубь активной области и вызывать окисление зеркала лазера даже без прямого контакта с атмосферным кислородом. Существуют и более сложные варианты пассивации поверхности, которые подразумевают нанесение нескольких слоев различных материалов $[2,6]$, один из которых выполняет пассивирующую функцию, а другой обеспечивает требуемый коэффициент отражения, или раскалывание гетероструктуры в вакууме [5,7]. Такие способы могут быть эффективны, но значительно усложняют про- цесс и делают его существенно дороже. В свою очередь пленки AlN, осажденные в атмосфере чистого азота, не содержат кислорода [8] и могут эффективно препятствовать окислению активной области лазера кислородом атмосферы. Благодаря своим оптическим и физическим свойствам (большой ширине запрещенной зоны, высокому показателю преломления, высокой теплопроводности и термостойкости, устойчивости к ряду агрессивных химических соединений) пленки на основе AlN могут одновременно обеспечивать генерацию когерентного излучения на заданной длине волны и служить защитой от проникновения атмосферного кислорода в активную область лазера. При этом для нанесения таких покрытий не требуется сложное и дорогостоящее оборудование и дорогие или опасные прекурсоры. Цель настоящей работы - методом атомно-силовой микроскопии оценить топографию поверхности различных образцов тонких пленок AlN и установить корреляцию между характером поверхности и показателем преломления полученных покрытий.

Пленки AlN осаждались на подложки epi-ready $n$-GaAs с ориентацией (100). Осаждение выполнялось методом реактивного ионно-плазменного распыления мишени из чистого алюминия $\mathrm{Al}(99.999 \%)$ в плазме особо чистого $\mathrm{N}_{2}$ на установке триодного типа. В процессе подготовки к осаждению пленок осуществлялась предварительная откачка камеры до давления не выше $2 \cdot 10^{-6}$ Torr, затем проводилось ионное травление мишени в плазме $\mathrm{Ar}^{+}$с целью очистить поверхность от окисла алюминия и возможных загрязнений. Давление в камере непосредственно перед напылением не превышало $1 \cdot 10^{-6}$ Torr. Давление рабочих газов в процессе ионной очистки 


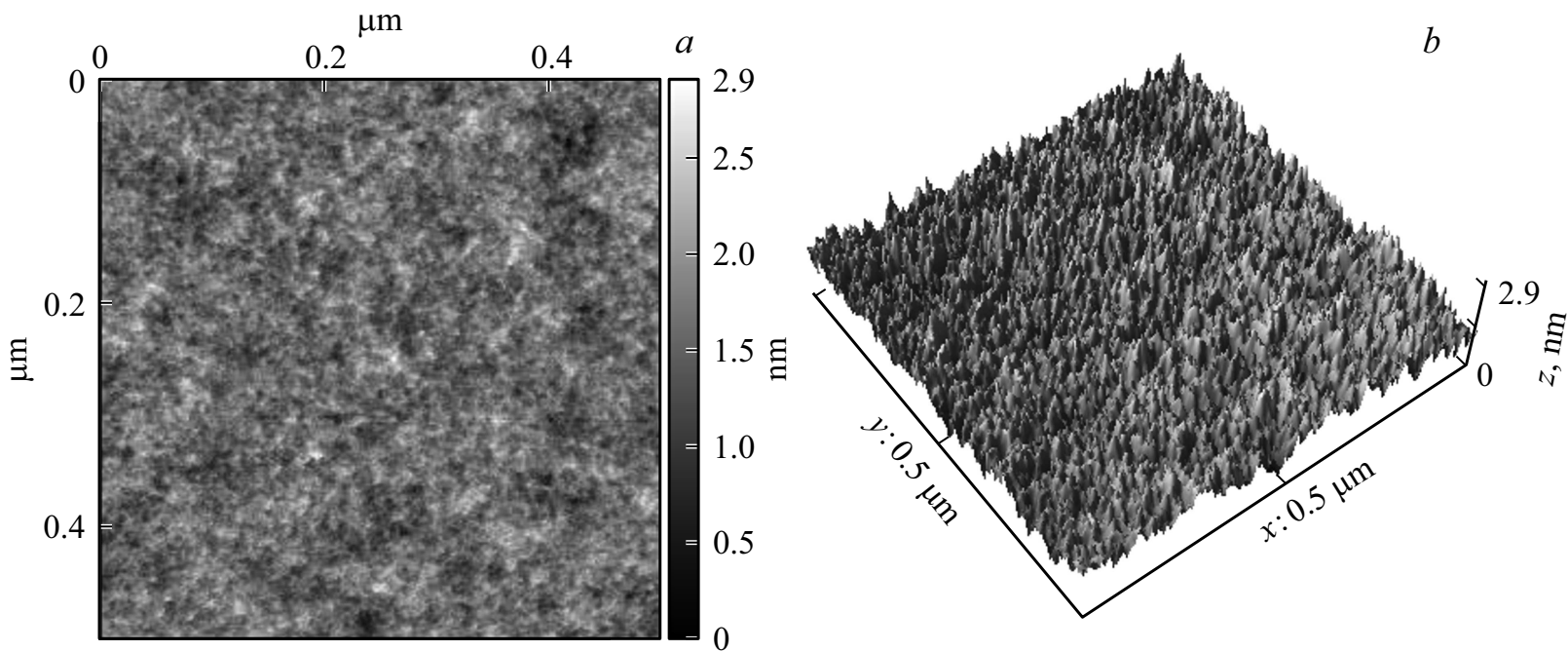

Рис. 1. Топография поверхности $(a)$ и псевдо-3D-изображение $(b)$ образца № 1 пленки AlN на подложке GaAs (100): малый радиус кривизны и латеральный размер зерна, низкая амплитуда перепада рельефа.
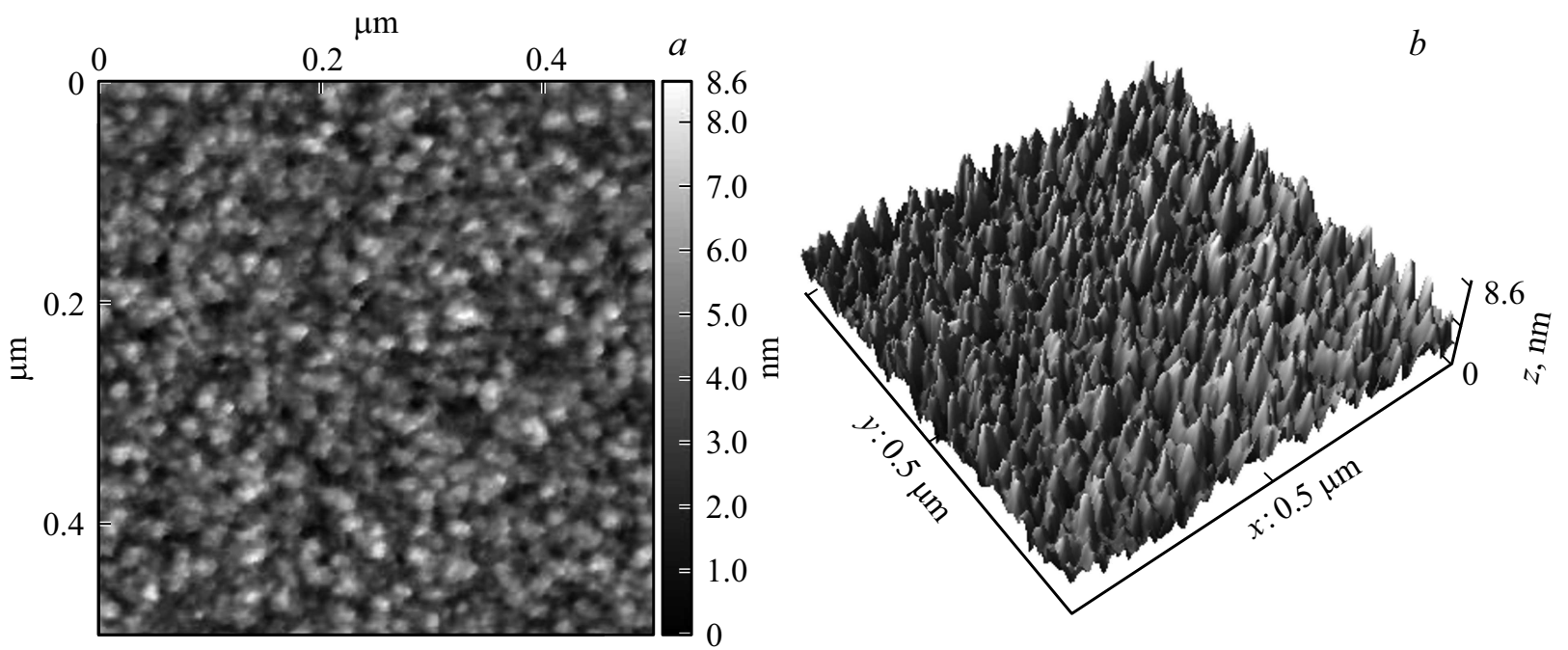

Рис. 2. Топография поверхности $(a)$ и псевдо-3D-изображение $(b)$ образца № 2 пленки AlN на подложке GaAs (100): амплитуда перепада рельефа, более чем вдвое превышающая таковую для контрольной подложки, и очень крупный латеральный размер указывают на более высокую степень кристалличности пленки.

и в процессе напыления покрытия поддерживалось на уровне $(3-5) \cdot 10^{-3}$ Torr. Чистота рабочих газов не хуже $99.999 \%$.

Толщина и показатель преломления полученных покрытий оценивались с помощью эллипсометра ЛЭФ-3М-1 на длине волны $\sim 633 \mathrm{~nm}$. Топография поверхности образцов была получена методом сканирующей зондовой микроскопии (C3M) в режиме „PeakForce Tapping“ на аппарате Bruker Dimension Icon (на базе центра NanoFab, UTT, Troyes, France), использовался зонд Bruker SCANASYST-AIR с номинальным радиусом кривизны кончика $2 \mathrm{~nm}$ и константой жесткости кантилевера $0.4 \mathrm{~N} / \mathrm{m}$. Анализ изображений СЗМ проводился с помощью программы Gwyddion [9].
Для работы была подготовлена серия образцов, полученных при различных параметрах технологического процесса. Измеренная толщина полученных пленок составляла $d=78.9-124.7 \mathrm{~nm}$. В зависимости от условий процесса скорость роста пленок менялась в диапазоне $v=6.07-15.59 \mathrm{~nm} / \mathrm{min}$, а показатель преломления варьировался в диапазоне $n=1.735-2.115$ для длины волны $633 \mathrm{~nm}$. Максимальный перепад высоты рельефа поверхности для разных образцов составлял $h=3-20 \mathrm{~nm}$. Латеральные размеры особенностей рельефа - зерен - оценим через диаметр $D$ диска, эквивалентного по площади проекции зерна на плоскость. Радиус кривизны зерна $R$ оценим следующим образом: 1) $R=D / 2$ при $D \sim 2 h$ или $D<2 h$; 

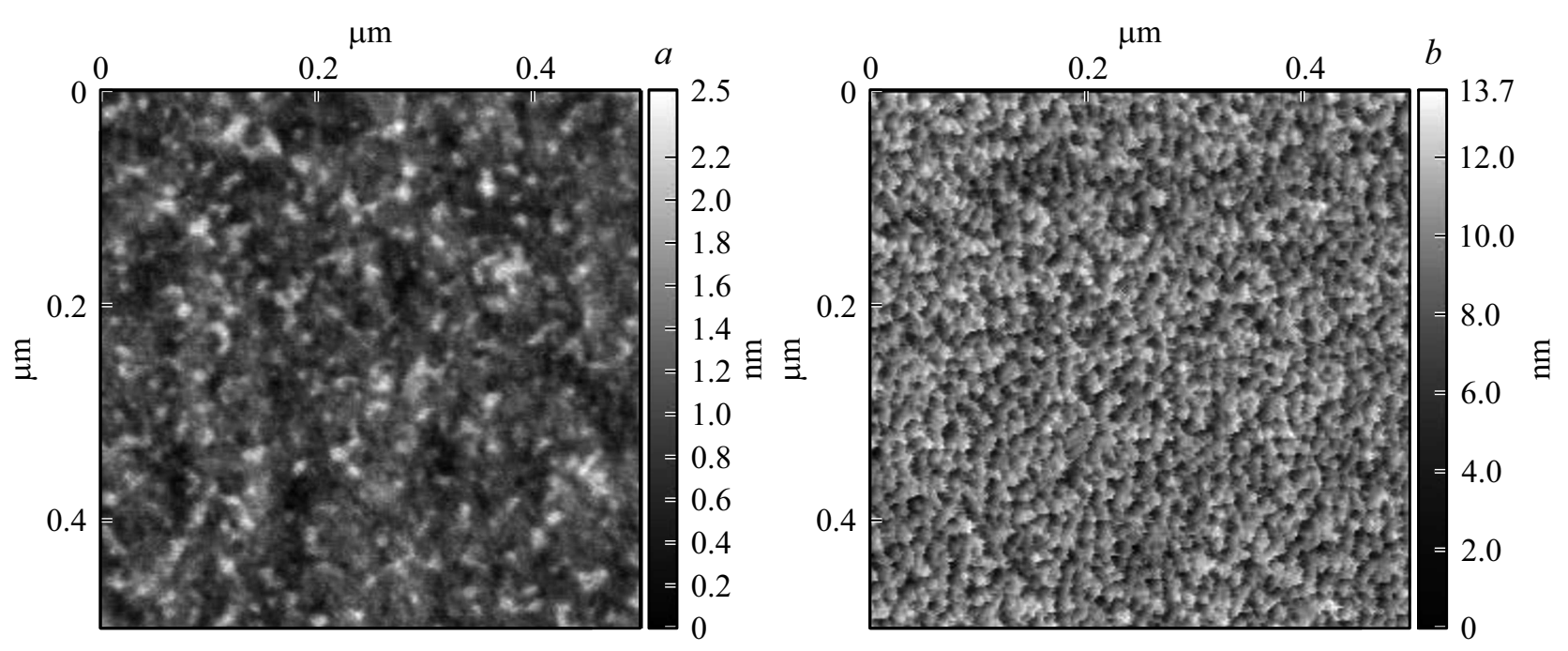

Pис. 3. Топография поверхности контрольной подложки $n$-GaAs (100) (a) и образца № 3 пленки AlN на подложке GaAs $(100)(b)$. Рельеф пленки значительно отличается от рельефа подложки, на которой она была выращена: очень высокая амплитуда рельефа при небольшом латеральном размере зерен.

Характеристики тонких пленок AlN

\begin{tabular}{c|c|c|c|c|c}
\hline Образец & Толщина $d, \mathrm{~nm}$ & $\begin{array}{c}\text { Показатель } \\
\text { преломления } n\end{array}$ & $\begin{array}{c}\text { Амплитуда рельефа } \\
\text { поверхности } h, \mathrm{~nm}\end{array}$ & $\begin{array}{c}\text { Средний диаметр } \\
\text { зерна } D, \mathrm{~nm}\end{array}$ & $\begin{array}{c}\text { Радиус кривизны } \\
\text { зерна } R, \mathrm{~nm}\end{array}$ \\
\hline № 1 & 124.7 & 1.735 & 2.9 & 7.1 & 3.5 \\
№ 2 & 123.4 & 2.115 & 8.6 & 12.3 & 6.1 \\
№ 3 & 83.8 & 2.056 & 13.7 & 7.3 & 3.6 \\
GaAs(100) & - & - & 2.5 & 8.7 & 5.0
\end{tabular}

2) $R=h / 2+(D / 2)^{2} / 2 h$ при $D>2 h$. Сводные данные представлены в таблице. При этом наблюдается корреляция показателя преломления с характером рельефа поверхности пленок. Так, для пленок с более крупной в латеральном или нормальном направлении текстурой поверхности характерен более высокий показатель преломления, чем для пленок с мелкой текстурой (рис. 1,2). Это может быть связано с тем, что полученные образцы имеют нанокристаллическую структуру, а размеры и ориентация кристаллитов зависят от условий роста. Показатель преломления пленок, имеющих более высокую степень кристалличности, состоящих из более крупных структурных элементов, стремится к показателю преломления монокристаллического $\mathrm{AlN}(n \sim 2.4)$, вместе с тем такие образцы имеют более выраженный рельеф поверхности. Корреляции между рельефом выращенной пленки и рельефом подложки GaAs (рис. 3) замечено не было, несмотря на то что подложка по данным СЗМ не является абсолютно гладкой. Можно заключить, что при толщине пленки выше некоторого значения нанорельеф подложки не должен оказывать влияния на объемную структуру пленки и ее оптические характеристики.

Высокие эксплуатационные характеристики, простота и дешевизна технологического процесса, а также возможность управлять показателем преломления в ши- роком диапазоне значений делают тонкие пленки AIN перспективным материалом для изготовления покрытий, выполняющих одновременно функцию пассивирующего и просветляющего покрытия для торцевых зеркалрезонаторов мощных полупроводниковых лазеров на основе материальной системы $\mathrm{AlGaAs} / \mathrm{GaAs}$.

Авторы благодарят коллектив кафедры фотоники СПбГЭТУ „ЛЭТИ“ и инженеров лаборатории LNIO UTT C.B. Кощеева, R. Deturche и J. Beal за помощь в проведении исследований и обсуждение полученных результатов.

\section{Список литературы}

[1] Анкудинов А.В., Евтихиев В.П., Токранов В.Е., Улин В.П., Титков А.Н. // ФТП. 1999. Т. 33. В. 5. С. 594-597.

[2] Beister G., Maege J., Erbert G., Tränkle G. // Solid-State Electron. 1998. V. 42. N 11. P. 1939-1945.

[3] Souto J., Pura J.L., Torres A., Jimenez J., Bettiati M., Laruelle F.J. // Microelectron. Reliab. 2016. V. 64. P. 627-630.

[4] Bessolov V.N., Lebedev M.V., Shernyakov Y.M., Tsarenkov B.V. // Mater. Sci. Eng. B. 1997. V. 44. N 1-3. P. 380-382.

[5] Ressel P., Erbert G., Zeimer U., Hausler K., Beister G., Sumpf B., Klehr A., Trankle G. // IEEE Photon. Technol. Lett. 2005. V. 17. N 5. P. 962-964. 
[6] Shu X., Xu C., Tian Z., Shen G. // Solid-State Electron. 2005. V. 49. N 12. P. 2016-2017.

[7] Chand N., Hobson W.S., de Jong J.F., Parayanthal P., Chakrabarti U.K. // Electron. Lett. 1996. V. 32. N 17. P. 1595 1596.

[8] Лубянский Я.В., Бондарев А.Д., Сошников И.П., Берт Н.А., Золотарев В.В., Кириленко Д.А., Котляр К.П., Пихтин Н.А., Тарасов И.С. // ФТП. 2018. Т. 52. В. 2. С. 196-200.

[9] Nečas D., Klapetek P. Gwyddion - free SPM data analysis software. www.gwyddion.net 